\title{
THE EFFECT OF ADRENOCORTICOTROPHIC HORMONE (ACTH) ON CEREBRAL BLOOD FLOW AND METABOLISM ${ }^{1}$
}

\author{
By JAMES F. SCHIEVE, 2 PERITZ SCHEINBERG, ${ }^{2}$ AND WILLIAM P. WILSON \\ (From the Department of Medicine and Department of Psychiatry, Duke University School of \\ Medicine, Durham, N. C.)
}

(Submitted for publication August 27, 1951; accepted September 10, 1951)

- While patients receiving adrenocorticotrophic hormone (ACTH) often show an increased sense of well-being and mild euphoria, a small number become psychotic. Electroencephalographic (EEG) changes (1) have been reported in patients receiving ACTH who become psychotic, but the changes have been inconsistently present. In one instance (2) the EEG changes appeared to be related to a decrease in serum potassium level.

These observations led to a study of cerebral blood flow and metabolism in patients receiving ACTH. Concurrent investigation of the EEG (3) and of the clinical and metabolic responses of these subjects will be reported elsewhere (4).

\section{METHOD}

A total of 44 observations on 14 patients was made; 15 before, 23 during, and six following ACTH treatment. ACTH was administered intramuscularly to adults in full therapeutic doses (60-100 mgs. Armour ACTH or 30 to 40 mgs. Wilson's Corticotropin daily).3 One 12 year old child received 33 mgs. Armour ACTH daily. There was no significant difference noted in the clinical response to the two brands of ACTH at these doses. Measurements were made at least once during therapy and as often as four times at intervals varying from seven to 56 days. In all patients, except one studied at seven days, at least one of the repeat studies was made between the second and third week on therapy. Several disease states are represented, including five patients with active rheumatoid arthritis, three with disseminated lupus erythematosis, and one each with subacute glomerulonephritis with edema, chronic glomerulonephritis, primary systemic amyloidosis, myasthenia gravis, chronic pulmonary fibrosis, and chronic exfoliative dermatitis. A All patients showed increased appetite and sense of well-being and

1 This work was supported by a grant from the $\mathrm{Na}$ tional Institutes of Health, Public Health Service and the Anna H. Hanes Memorial Fund.

2 American Heart Association Research Fellow.

8 We are indebted to Dr. John R. Mote of the Armour Laboratories, Chicago, Illinois, and Dr. David Klein of the Wilson Laboratories, Chicago, Illinois, for generous supplies of ACTH for these studies. most developed the facial fullness and redness suggestive of Cushing's syndrome.

All of the patients were studied under similar laboratory conditions in the fasting state. The nitrous oxide method originally described by Kety and Schmidt (5) and modified by Scheinberg and Stead (6) was used. The gas mixture used in the determination consisted of approximately $15 \% \mathrm{~N}_{2} \mathrm{O}, 64 \% \mathrm{~N}_{2}$, and $21 \% \mathrm{O}_{2}$. Arterial blood pressure was measured by the auscultatory method with the arm held at heart level. Mean arterial blood pressures were calculated from these readings by adding one third of the pulse pressure to the diastolic pressure. Blood samples for determination of oxygen and glucose contents were drawn just before and following each cerebral blood flow. The A-V oxygen difference was determined by the method described by Hickam and Frayser (7). The blood glucose content was measured by Nelson's (8) photometric adaptation of the Somogyi method. Cerebral oxygen and glucose utilizations were calculated as previously described $(5,6)$.

\section{RESULTS}

The results summarized in Table I show a statistically significant decrease in cerebral blood flow on ACTH treatment from 61 to $50 \mathrm{ml} . / \mathrm{min} . / 100$ gm. brain. After approximately 14 days on therapy no further decrease in cerebral blood flow oc-

TABLE I

Effect of ACTH on cerebral blood flow and metabolism

(Mean values of 44 determinations on 14 subjects)

\begin{tabular}{l|c|c|c}
\hline \hline & $\begin{array}{c}\text { No ACTH } \\
(21 \\
\text { Determ.) }\end{array}$ & $\begin{array}{c}\text { On ACTH } \\
(23 \\
\text { Determ.) }\end{array}$ & P-Value \\
\hline $\begin{array}{l}\text { CBF } \\
\text { (ml./min./100 gm. brain) }\end{array}$ & $61 \pm 3.2$ & $50.0 \pm 2.0$ & 0.01 \\
$\begin{array}{l}\text { A-V O2 Diff. } \\
\text { (vols. \%) }\end{array}$ & $5.8 \pm .22$ & $6.5 \pm .23$ & 0.05 \\
$\begin{array}{l}\text { A-V G1. Diff. } \\
\text { (mgs. \%) }\end{array}$ & $8.2 \pm .50$ & $10.1 \pm .45$ & 0.02 \\
$\begin{array}{l}\text { CMR O2 } \\
\text { (ml. O2/min./100 gm. brain) }\end{array}$ & $3.5 \pm .50$ & $3.2 \pm .33$ & Not significant \\
$\begin{array}{l}\text { CMR Gl. } \\
\text { (mg. glucose/min./100 gm. } \\
\text { brain) }\end{array}$ & $4.9 \pm .40$ & $4.9 \pm .24$ & Not significant \\
$\begin{array}{l}\text { MABP } \\
\text { (mm. Hg) }\end{array}$ & $90 \pm 2.0$ & $98 \pm 2.7$ & 0.05 to 0.01 \\
$\begin{array}{l}\text { CVR } \\
\text { (units) }\end{array}$ & $1.6 \pm .12$ & $2.1 \pm .14$ & 0.05 to 0.01 \\
\hline
\end{tabular}


curred in spite of continued full ACTH dosage. The arterial-cerebral venous oxygen and glucose differences were increased and hence there was no demonstrable change in cerebral utilization of oxygen and glucose (CMR $\mathrm{O}_{2}$ and CMR G1.). During ACTH therapy a $9 \%$ increase in mean arterial blood pressure (MABP) occurred. There was; however, a $32 \%$ increase in cerebral vascular resistance (CVR) since the decrease in cerebral blood flow was greater than the rise in mean arterial blood pressure.

Six patients with normal or high pre-treatment cerebral blood flows had studies performed both before initiation and after discontinuation of $\mathrm{ACTH}$ therapy. In this group there was only a $3 \mathrm{ml}$./ min./100 gm. brain difference and thus the before and after flows have been grouped together in the column labeled "No ACTH" in Table I.

There were six patients included in Table I whose cerebral blood flow before ACTH therapy was below $50 \mathrm{ml} . / \mathrm{min} . / 100 \mathrm{gm}$. brain. These patients also showed low oxygen and glucose consumption by the brain. In these six patients ACTH treatment was not associated with further reduction in cerebral blood flow (46 to $45 \mathrm{ml}$./ min./100 gm. brain), nor was oxygen consumption (2.8 to $2.9 \mathrm{ml} . \mathrm{O}_{2} / \mathrm{min}$./100 gm. brain) significantly altered. Although these patients did develop a similar slight hypertension as did the group with normal initial flows, no significant change in cerebral vascular resistance occurred. The clinical response to ACTH treatment was similar regardless of the original level of cerebral blood flow.

Two patients were studied before, during and following a psychotic episode which developed during ACTH therapy. These studies were not different from the cerebral blood flow changes which occurred in other patients receiving ACTH who did not become psychotic. Thus psychotic behavior during ACTH therapy was not associated with change in cerebral metabolism as measured by this method. Serial EEG studies were done on all patients (3). In 12 there was no gross change in the EEG pattern, including the two patients who had tracings during their period of psychosis. Definite improvement in EEG pattern was found on therapy in two patients. There appeared to be no correlation between changes in cerebral blood flow and EEG patterns. Nor was it possible to correlate changes in plasma carbon dioxide combining power or serum potassium levels with changes in either cerebral blood flow or mental status.

\section{DISCUSSION}

The results show ACTH significantly decreased cerebral blood flow without changing cerebral oxygen and glucose consumption. This response, occurs before or by the end of the second week of therapy, and seems to persist unchanged as long as the therapy is continued. The effect is reversible in that cerebral blood flow returns to pre-treatment levels within a few days after discontinuation of treatment with ACTH. In patients with abnormally low pre-treatment cerebral blood flow ACTH did not change either cerebral blood flow or cerebral metabolism.

How ACTH decreases cerebral blood flow is unknown. The decrease in cerebral blood flow could be related to generalized increase in peripheral resistance, to a decrease in cardiac output, or to a localized increase in resistance in the cerebral circulation. The rise in arterial pressure is less than would be expected if the peripheral resistance as a whole had increased to the same extent as the resistance in the cerebral vessels. In fragmentary preliminary studies, ACTH has not consistently changed cardiac output (9-11). Horwitz and colleagues have reported that the cardiac output frequently decreases in those instances in which ACTH produces a fall in heart rate. The best explanation from the available data is a local increase in cerebral vascular resistance of unknown etiology.

A reduction in cerebral blood flow out of proportion to the general increase in peripheral resistance has been observed in subjects breathing $85 \%$ oxygen and during hyperventilation (12). The cerebral metabolism of oxygen and glucose is normally maintained by simultaneous and adequate widening of their respective $\mathrm{A}-\mathrm{V}$ differences.

It is well known that cerebral vessels are extremely sensitive to changes in blood $\mathrm{pH}(12)$ and carbon dioxide content. In respiratory alkalosis a decrease in cerebral blood flow does occur. In a few patients with Cushing's disease and occasionally in those receiving ACTH metabolic alkalosis develops. The production of metabolic alkalosis in humans with $3 \%$ sodium bicarbonate intrave- 
nously (13) has been found to increase cerebral blood flow markedly without changing cerebral metabolic rate. Thus it seems unlikely that metabolic alkalosis was responsible for the decrease in cerebral blood flow. It is known that hypothyroidism develops on prolonged ACTH treatment (14). The patients in this study, however, did not have any decrease in cerebral metabolic rate of oxygen consumption which characterized those patients studied by Scheinberg (15) with hypothyroidism.

\section{SUMMARY AND CONCLUSIONS}

1. Studies of cerebral blood flow and metabolism were made on 14 patients receiving $\mathrm{ACTH}$ for various diseases.

2. An $18 \%$ decrease in cerebral blood flow occurred during ACTH therapy. This was associated with a $32 \%$ increase in cerebral vascular resistance and $9 \%$ increase in mean arterial blood pressure. These changes were accompanied by significant widening of arterial-cerebral venous oxygen and glucose differences, and hence no change in cerebral metabolic utilization of oxygen or glucose.

3. The decrease in cerebral blood flow during ACTH treatment occurs before or by the end of the second week, apparently persists unchanged on continued therapy, and returns to pre-treatment levels within several days after discontinuing ACTH.

4. No information was found by this method to explain either the sense of well-being or the psychotic episodes which occur during ACTH therapy.

\section{REFERENCES}

1. Hoefer, P. F. A., and Glaser, G. H., Effects of pituitary adrenocorticotrophic hormone (ACTH) therapy. Electroencephalographic and neuropsychiatric changes in fifteen patients. J.A.M.A., 1950, 143, 620 .

2. Ransohoff, W., Brust, A. A., Reiser, M. F., Mirsky, I. A., and Ferris, E. B., The effect of sodium and potassium on the metabolic and physiologic responses to ACTH. J. Lab. \& Clin. Med., 1950, 36, 978.
3. Pine, I., Engel, F. L., and Schwartz, T. B., The EEG in ACTH and cortisone treated patients. Electroencephalog. \& Clin. Neurophysiol., in press, 1951.

4. Schwartz, T. B., and Engel, F. L., To be published.

5. Kety, S. S., and Schmidt, C. F., The determination of cerebral blood flow in man by the use of nitrous oxide in low concentrations. Am. J. Physiol., 1945, 143, 53.

6. Scheinberg, P., and Stead, E. A., Jr., The cerebral blood flow in male subjects as measured by the nitrous oxide technique. Normal values for blood flow, oxygen utilization, glucose utilization, and peripheral resistance, with observations on the effects of tilting and anxiety. J. Clin. Invest., 1949, 28, 1163.

7. Hickam, J. B., and Frayser, R., Spectrophotometric determination of blood oxygen content. J. Biol. Chem., 1949, 180, 457.

8. Nelson, N., A photometric adaptation of the Somogyi method for the determination of glucose. J. Biol. Chem., 1944, 153, 375.

9. Sayen, A., Horwitz, O., and Stroud, M. R., 3rd, Digital cutaneous blood flow, cardiac output, blood pressure and pulse rate immediately following the administration of four potential vasodilators. Am. J. Med. Sci., 1951, 221, 667.

10. Horwitz, O., Sayen, A., Naide, M., and Hollander, J. L., Measurements of certain cardiovascular responses to ACTH and cortisone in man. Am. J. Med. Sci., 1951, 221, 669.

11. Brust, A. A., Ransohoff, W., Reiser, M. F., and Ferris, E. B., Vascular responses to ACTH and alterations in sodium intake, in Proceedings of the Second Clinical ACTH Conference. Blakiston Company, Philadelphia, 1951, 1, 177.

12. Kety, S. S., and Schmidt, C. F., The effects of altered arterial tensions of carbon dioxide and oxygen on cerebral blood flow and cerebral oxygen consumption of normal young men. J. Clin. Invest., 1948, 27, 484.

13. Schieve, J. F., and Wilson, W. P., The effect of experimentally induced metabolic alkalosis on cerebral blood flow. To be published.

14. Wolfson, W. Q., Beierwaltes, W. H., Robinson, W. D., Duff, I. F., Jones, J. R., Knorpp, C. T., and Eya, M., Corticogenic hypothyroidism: Its regular occurrence and clinical significance during prolonged therapeutic administration of $\mathrm{ACTH}$ or cortisone. J. Lab. \& Clin. Med., 1950, 36, 1005.

15. Scheinberg, P., Cerebral metabolism in hyperthyroidism and myxedema. Federation Proc., 1950, 9, 113. 